\title{
PENENTUAN NITRIT DALAM IKAN BAWAL PUTIH (Pampus argenteus) MENGGUNAKAN REAGEN 3-AMINA-7-DIMETILAMINA-2-METILFENAZIN HIDROKLORIDA DENGAN SPEKTROFOTOMETER VISIBEL
}

Tritiyatma Hadinugrahaningsih, Irma Ratna Kartika, dan Susy Saadah

Jurusan Kimia, Fakultas MIPA, Universitas Negeri Jakarta, Jl. Pemuda No. 10 Rawamangun Jakarta 13220, Indonesia

Corresponding author: nunuk_prabowo@yahoo.com

\begin{abstract}
Abstrak
Penelitian ini bertujuan untuk menentukan kadar nitrit dalam ikan bawal putih (Pampus argenteus) dengan variasi waktu penyimpanan menggunakan reagen 3-amina-7-dimetilamina-2-metilfenazin hidroklorida. Sampel ikan bawal putih (Pamppus argenteus) diperoleh dari hasil tangkapan nelayan Muara Angke. Kadar nitrit dalam ikan bawal putih (Pampus argenteus) ditentukan menggunakan metode spektrofotometri. Dari hasil penelitian, diketahui bahwa, konsentrasi optimum reagen 3-amina-7-dimetilamina-2-metilfenazin hidroklorida adalah 0,0021\% (b/v). Kadar nitrit dalam daging ikan bawal putih (Pampus argenteus) melalui proses freeze dry saat didiamkan selama satu hari adalah sebesar 5,388ppm, sedangkan tanpa melalui freeze dry adalah sebesar 4,085ppm. Kadar nitrit dalam daging ikan bawal putih (Pampus argenteus) melalui proses freeze dry saat didiamkan selama empat belas hari adalah sebesar 28,89ppm, sedangkan tanpa melalui freeze dry adalah sebesar 18,53ppm. Semakin lama ikan bawal putih (Pampus argenteus) didiamkan, maka konsentrasi nitrit yang terkandung semakin meningkat. Tidak terdapat perbedaan antara konsentrasi nitrit dalam daging ikan bawal (Pampus argenteus) yang mengalami proses freeze dry dan tidak mengalami proses freeze dry.
\end{abstract}

Kata kunci: $\quad$ Nitrit, ikan bawal putih, Pampus argenteus, 3-amina-7-dimetilamina-2-metilfenazin hidroklorida, freeze dry

\begin{abstract}
The aim of the research is to determine nitrite level in the silver pomfret (pampus argenteus) with various storage using 3-amino-7-dimethylamino-2-methyl phenazine hydrochloride reagent. The fresh fish purchase from Muara Angke fisherman. Nitrite level of silver pomfret is determined by spectrophotometer method. The results showed that the optimum concentration of 3-amino-7-dimethylamino-2-methyl phenazine hydrochloride reagent is $0.0021 \%(b / v)$. The fish was stored using overnight freeze drying process. The nitrite level of overnight fish is $5.388 \mathrm{ppm}$ and without freeze drying process is $4,085 \mathrm{ppm}$. The nitrite level of fish on day 14 is $28.89 p p m$, and without freeze drying process is $18.53 p p m$. The storage time of fish is linearly proportinonal to nitrite level which is using or without using freeze drying process.
\end{abstract}

Key words: $\quad$ Nitrite, Pampus argenteus, 3-amine-7-dimethylamine-2-methylphenazine hydrochloride, freeze dry

\section{Pendahuluan}

Nitrit merupakan hasil senyawa antara pada proses nitrifikasi dan denitrifikasi. Di alam, nitrit sudah diubah menjadi bentuk nitrat atau bentuk lainnya [1]. Enzim nitrat reduktase dan nitrit reduktase mengubah nitrat dalam tubuh manusia menjadi amonia melalui zat antara yaitu nitrit. Nitrat digunakan sebagai akseptor elektron untuk memperoleh energi yang akan digunakan untuk mendegradasi senyawa organik ketika kadar oksigen rendah. Amonia yang dihasilkan dikeluarkan melalui urin [2].

Efek racun yang akut dari nitrit adalah methemoglobinemia yaitu lebih dari $10 \%$ hemoglobin diubah menjadi methemoglobin. Methemoglobinemia merupakan keadaan ketika darah tidak mampu mengangkut oksigen. Bila konversi ini melebihi 70\% maka akan berakibat sangat fatal [3]. Efek yang paling berbahaya apabila mengkonsumsi nitrit dalam jumlah berlebih adalah menaikkan 
risiko terkena penyakit kanker saluran cerna yang mampu mengakibatkan kematian ${ }^{4}$.

Nitrit merupakan senyawa yang larut dalam air sehingga banyak nitrit yang terkandung di dalam perairan. Salah satu perairan yang terdapat di sekitar Jakarta adalah Muara Angke. Kadar nitrit di Muara Angke sudah mencapai tahap yang mengkhawatirkan. Kadar nitrit di Muara Angke sebesar $17,48 \times 10^{-3} \mathrm{ppm}$ sedangkan ambang batas kadar nitrit dalam air laut sebesar $2 \times 10^{-5}$ ppm [5]. Nitrit yang terkandung dalam air laut dapat terakumulasi dalam daging ikan [6]. Ikan bawal putih (Pampus argenteus) merupakan ikan yang terus mengalami peningkatan konsumsi sebesar 5,34\% sejak tahun 2002 hingga 2006 [7]. Nitrit akan terakumulasi dalam ikan bawal putih (Pampus argenteus) yang banyak terdapat di Muara Angke.

Apabila nitrit tersebut terakumulasi di tubuh manusia dalam kadar yang cukup tinggi, kemungkinan besar akan mengakibatkan penyakit-penyakit seperti yang telah dijelaskan sebelumnya. Reagen yang sering digunakan untuk menganalisis kadar nitrit adalah sulfanilamida dan $\mathrm{N}$ dihidroklorida-1naftiletilendiamin atau yang lebih sering dikenal sebagai reagen Griess [8]. Namun metode ini memiliki kelemahan, yaitu pembentukan senyawa azo memerlukan waktu selama 30 menit di tempat gelap dan membutuhkan banyak reagen. Reagen lain yang biasa digunakan dalam penentuan nitrit adalah senyawa 3-amina-7-dimetilamina-2metilfenazin hidroklorida [9]. Senyawa ini tidak membutuhkan waktu yang lama dalam pembentukan senyawa azonium dan hanya menggunakan satu reagen.

Oleh karena itu, pada penelitian ini akan dilakukan optimasi konsentrasi senyawa 3amina-7-dimetilamina-2-metilfenazin

hidroklorida dalam penentuan nitrat dan nitrit, yang kemudian diaplikasikan untuk penentuan nitrit dalam ikan bawal putih (Pampus argenteus).

\section{Metodologi Penelitian}

\subsection{Bahan Kimia}

Bahan yang digunakan adalah ikan bawal putih (Pampus argenteus) berasal dari tangkapan nelayan di Muara Angke, larutan asam sulfat, larutan kalium bromida, larutan natrium nitrit, larutan 3-amina-7dimetilamina-2-metilfenazin hidroklorida, larutan natrium karbonat, larutan natrium hipofosfit, larutan sulfanilamida, larutan N dihidroklorida-1-naptiletilendiamin (NED), larutan asam klorida pekat dan akuades. Seluruh bahan menggunakan merk Merck.

\subsection{Alat-alat yang Digunakan}

Alat-alat yang digunakan adalah spektrofotometer visibel Shimadzu 1601 V, blender Philips HR 2071, freeze drying Labtop Lypophilization, grinder Philips HL-1606, sentrifuge Adam 0151, neraca analitik Wiggen Hauser, spatula dan alat-alat gelas lainnya. Seluruh alat gelas menggunakan merk Pyrex.

Optimasi Konsentrasi dalam Penentuan Nitrit

Sebanyak $2 \mathrm{~mL}$ larutan 3-amina-7dimetilamina-2-metilfenazin hidroklorida $0,001 \%(\mathrm{~b} / \mathrm{v}), 1 \mathrm{~mL}$ asam sulfat $4,25 \mathrm{M}$ dan $1 \mathrm{~mL}$ kalium bromida $1 \%$ dimasukkan ke dalam labu ukur $25 \mathrm{~mL}$. Langkah ini kemudian diulang menggunakan larutan 3-amina-7dimetilamina-2-metilfenazin hidroklorida dengan konsentrasi yang berbeda yaitu $0,002 \%(b / v), 0,003 \%(b / v), 0,004 \%(b / v)$ atau $0,005 \%$ (b/v). Selanjutnya ditambah $10 \mathrm{~mL}$ larutan standar yang mengandung $0,1 \mathrm{mg}$ nitrit dalam $100 \mathrm{~mL}$, lalu ditambah $1 \mathrm{~mL}$ natrium hipofosfit $1 \%$, diaduk hingga homogen. Selanjutnya diencerkan hingga tanda batas kemudian absorbansi diukur pada panjang gelombang $545 \mathrm{~nm}$.

2.4 Pembuatan Kurva Kalibrasi Absorbansi vs Konsentrasi Larutan Standar Nitrit dengan Reagen 3-Amina-7-Dimetilamina-2 Metilfenazin Hidroklorida 
Sebanyak $2 \mathrm{~mL}$ larutan 3-amina-7dimetilamina-2-metilfenazin hidroklorida yang telah dioptimasi konsentrasinya ditambah $1 \mathrm{~mL}$ asam sulfat $4,25 \mathrm{M}$ dan $1 \mathrm{~mL}$ kalium bromida 1\% kemudian dimasukkan ke dalam labu ukur $25 \mathrm{~mL}$. Selanjutnya ditambah $10 \mathrm{~mL}$ larutan standar nitrit $1 \mathrm{ppm}$ lalu ditambah $1 \mathrm{~mL}$ natrium hipofosfit 1\%, diaduk hingga homogen. Langkah ini kemudian diulang menggunakan larutan nitrit dengan konsentrasi yang berbeda $1 \mathrm{ppm}, 5 \mathrm{ppm}$, $10 \mathrm{ppm}, 15 \mathrm{ppm}, 20 \mathrm{ppm}, 25 \mathrm{ppm}, 30 \mathrm{ppm}$, 40ppm dan 45ppm. Selanjutnya diencerkan hingga tanda batas setelah itu absorbansi diukur pada panjang gelombang $545 \mathrm{~nm}$. Data absorbansi yang diperoleh diplotkan dalam kurva kalibrasi absorbansi vs konsentrasi larutan standar nitrit.

Tabel 1. Optimasi Konsentrasi 3-Amina-7Dimetilamina-2-Metilfenazin Hidroklorida

\begin{tabular}{|c|c|}
\hline Konsentrasi \% (b/v) & Absorbansi \\
\hline 0,0013 & 0,011 \\
\hline 0,0017 & 0,014 \\
\hline 0,0021 & 0,024 \\
\hline 0,0026 & 0,017 \\
\hline 0,0031 & 0,013 \\
\hline 0,0040 & 0,009 \\
\hline 0,0050 & 0,005 \\
\hline 0,0061 & 0,003 \\
\hline
\end{tabular}

2.5. Penentuan Kadar Nitrit dalam Ikan Bawal Putih (Pampus argenteus) Melalui Proses Freeze Dry dengan Variasi Waktu Penyimpanan

Ikan bawal putih (Pampus argenteus) dengan variasi waktu penyimpanan 1 hari, 3 hari, 7 hari, 9 hari, 11 hari dan 14 hari yang diperoleh dari tangkapan nelayan di Muara
Tabel 2. Absorbansi vs Konsentrasi Larutan Standar Pada Reagen 3-Amina-7-Dimetilamina-2Metilfenazin Hidroklorida

\begin{tabular}{|c|c|}
\hline $\begin{array}{c}\text { Konsentrasi } \\
\text { Larutan (ppm) }\end{array}$ & Absorbansi \\
\hline 0 & 0,000 \\
\hline 1 & 0,023 \\
\hline 5 & 0,041 \\
\hline 10 & 0,064 \\
\hline 15 & 0,082 \\
\hline 20 & 0,106 \\
\hline 25 & 0,131 \\
\hline 30 & 0,167 \\
\hline 35 & 0,198 \\
\hline 40 & 0,224 \\
\hline 45 & 0,259 \\
\hline
\end{tabular}

Angke dibersihkan terlebih dahulu, dipotong, diambil hanya bagian daging ikan tersebut. Fillet ikan yang diperoleh kemudian dihancurkan menggunakan blender. Fillet yang telah hancur selanjutnya difreeze-drykan menggunakan alat frezee drying. Fillet beku kemudian digiling menggunakan grinder, diayak, lalu disimpan dalam kemasan tertutup.

Sampel sebesar 0,5000 gram dimasukkan ke dalam gelas kimia $25 \mathrm{~mL}$. Setelah itu, sampel diekstraksi menggunakan $5 \mathrm{~mL}$ natrium karbonat $0,5 \%$ sebanyak tiga kali pengulangan. Selanjutnya, ekstrak disaring menggunakan kertas saring Whatman 41. Filtrat yang diperoleh kemudian dikumpulkan lalu diencerkan dengan akuades hingga $25 \mathrm{~mL}$. Langkah selanjutnya untuk penentuan nitrit sesuai dengan prosedur 2.4. dengan konsentrasi 3-amina-7-dimetilamina-2metilfenazin hidroklorida yang telah dioptimasi.

2.6 Penentuan Kadar Nitrit dalam Ikan Bawal Putih (Pampus argenteus) Tanpa Melalui Proses Freeze Dry dengan Variasi Waktu Penyimpanan 


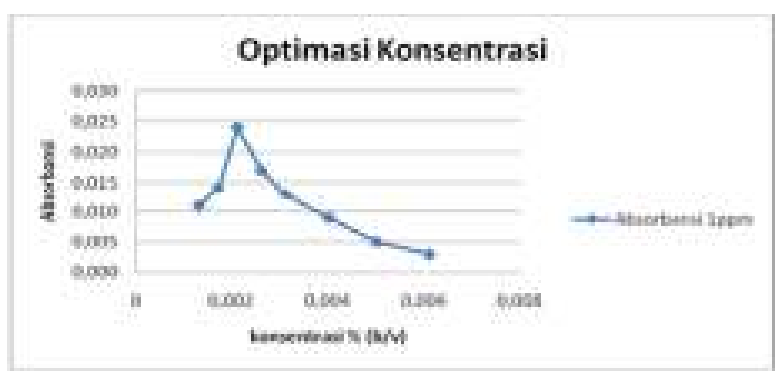

Gambar 1. Grafik Optimasi Konsentrasi 3-Amina-7-Dimetilamina-2Metilfenazin Hidroklorida

Ikan bawal putih (Pampus argenteus) dengan variasi waktu penyimpanan 1 hari, 3 hari, 7 hari, 9 hari, 11 hari dan 14 hari yang diperoleh dari tangkapan nelayan di Muara Angke dibersihkan terlebih dahulu, dipotong, diambil hanya bagian daging ikan tersebut. Fillet ikan yang diperoleh kemudian dihancurkan menggunakan blender. Fillet kemudian digiling menggunakan grinder, diayak, lalu disimpan dalam kemasan tertutup.

\section{Hasil dan Pembahasan}

\subsection{Optimasi Konsentrasi 3-Amina-7-}

Dimetilamina-2-Metilfenazin Hidroklorida

Sebelum direaksikan dengan nitrit, reagen 3-amina-7-dimetilamina-2-metilfenazin hidroklorida ditambah asam sulfat dan kalium bromida. Hal ini dilakukan untuk mencegah nitrit teroksidasi menjadi nitrat.

$$
2 \mathrm{KBr}+2 \mathrm{H}_{2} \mathrm{SO}_{4} \rightarrow \mathrm{Br}_{2}+\mathrm{SO}_{2}+\mathrm{SO}_{4}{ }^{2}+2 \mathrm{~K}^{+}+2 \mathrm{H}_{2} \mathrm{O}
$$

Selain itu, penambahan asam sulfat berfungsi untuk memberikan suasana asam karena reaksi antara 3-amina-7-dimetilamina2-metilfenazin hidroklorida dengan nitrit hanya dapat berlangsung dalam suasana asam.

$\mathrm{C}_{15} \mathrm{~N}_{4} \mathrm{H}_{17} \mathrm{Cl}+\mathrm{NO}_{2}^{-} \rightarrow \mathrm{C}_{15} \mathrm{~N}_{2} \mathrm{H}_{17} \mathrm{~N}_{2}^{+-} \mathrm{Br} \rightarrow \mathrm{C}_{15} \mathrm{~N}_{2} \mathrm{H}_{17}$

Selanjutnya, ditambah $10 \mathrm{~mL}$ larutan standar nitrit $1 \mathrm{ppm}$, lalu ditambah natrium hipofosfit untuk memaksimalkan pencegahan nitrit teroksidasi menjadi nitrat. Hal ini dilakukan karena nitrat tidak dapat bereaksi dengan reagen 3-amina-7-dimetilamina-2metilfenazin hidroklorida. Apabila nitrit teroksidasi menjadi nitrat maka jumlah nitrit yang bereaksi dengan reagen 3-amina-7dimetilamina-2-metilfenazin hidroklorida berkurang sehingga absorbansi yang didapat tidak maksimal.

Tabel 3. Absorbansi vs Konsentrasi Larutan Standar Pada Reagen Griess

\begin{tabular}{|c|c|}
\hline Konsentrasi Larutan (ppm) & Absorbansi \\
\hline 0 & 0,000 \\
\hline 1 & 0,003 \\
\hline 5 & 0,024 \\
\hline 10 & 0,059 \\
\hline 15 & 0,089 \\
\hline 20 & 0,119 \\
\hline 25 & 0,143 \\
\hline 30 & 0,175 \\
\hline 35 & 0,192 \\
\hline 40 & 0,243 \\
\hline 45 & 0,293 \\
\hline
\end{tabular}

$\mathrm{NaH}_{2} \mathrm{PO}_{2}+4 \mathrm{H}_{2} \mathrm{SO}_{4} \rightarrow \quad 2 \mathrm{SO}_{2}+\mathrm{H}_{3} \mathrm{PO}_{4}+3 \mathrm{H}^{+}+$ $\mathrm{Na}^{+}+2 \mathrm{SO}_{4}{ }^{2-}+2 \mathrm{H}_{2} \mathrm{O}$

Konsentrasi 3-amina-7-dimetilamina-2metilfenazin hidroklorida perlu dioptimasi untuk mengetahui jumlah pereaksi minimum 


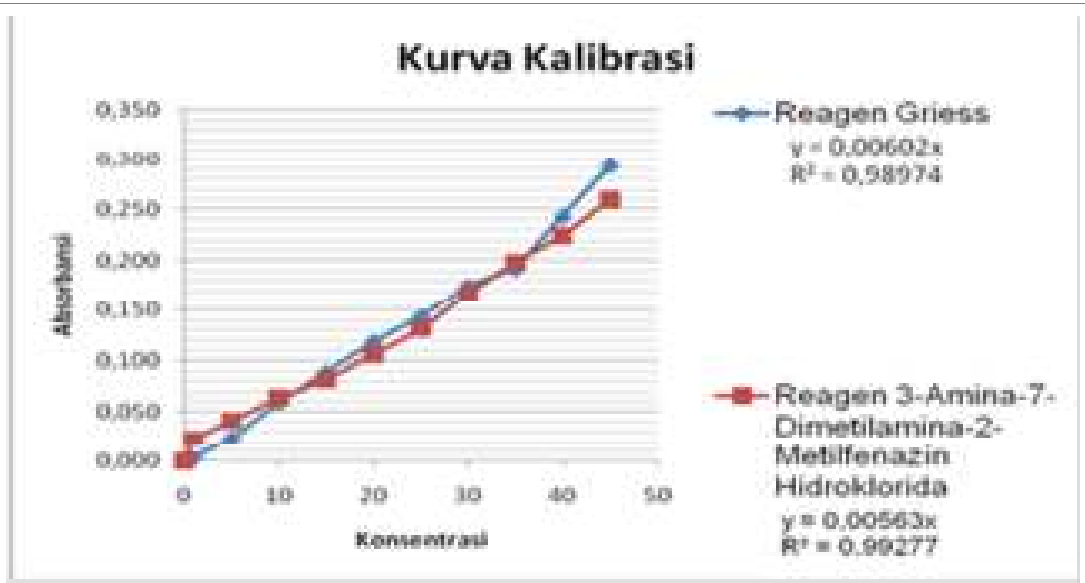

Gambar 2. Grafik Absorbansi vs Konsentrasi Larutan Standar Pada Reagen 3Amina-7-Dimetlamina 2-Metilfenazin Hidroklorida dan Reagen Griess

yang harus aua aaram ırucan, senıngga semua analit nitrit dapat terkomplekskan. Jumlah pereaksi yang cukup tersebut diharapkan tidak terlalu berlimpah agar tidak mengganggu jalannya reaksi. Nilai absorbansi menunjukkan jumlah analit nitrit yang telah membentuk kompleks dengan reagen 3amina-7-dimetilamina-2-metilfenazin

hidroklorida. Nilai absorbansi terbesar menunjukkan konsentrasi nitrit maksimal yang bereaksi dengan reagen 3-amina-7dimetilamina-2-metilfenazin hidroklorida.

Konsentrasi 3-amina-7-dimetilamina-2metilfenazin hidroklorida dengan nilai absorbansi terbesar menunjukkan konsentrasi optimum reagen tersebut. Berdasarkan Tabel 1 dan Gambar 1, konsentrasi optimum 3amina-7-dimetilamina-2-metilfenazin hidroklorida adalah 0,0021\% (b/v).

\subsection{Pembuatan Kurva Kalibrasi}

Larutan standar dibuat dengan cara mengencerkan larutan induk 100ppm hingga diperoleh konsentrasi yang diinginkan. Persamaan garis absorbansi vs konsentrasi larutan standar natrium nitrit digunakan untuk memperoleh konsentrasi nitrit yang terkandung dalam sampel berupa ikan bawal putih (Pampus argenteus). Nilai absorbansi larutan standar nitrit yang diperoleh menggunakan reagen 3-amina-7dimetilamina-2-metilfenazin hidroklorida disajikan pada Tabel 2. Kurva kalibrasi absorbansi vs konsentrasi larutan standar disajikan pada Gambar 2. Persamaan garis absorbansi vs konsentrasi larutan standar natrium nitrit yang diperoleh adalah sebesar $y=0,00563 x$ dengan regresi sebesar 0,99277 .

Tabel 4. Kadar Nitrit dalam Daging Ikan Bawal Putih (Pampus argenteus) dengan Variasi Waktu Penyimpanan Melalui Proses Freeze Dry Menggunakan Reagen 3-amina-7-dimetilamina-2metilfenazin Hidroklorida

\begin{tabular}{|c|c|}
\hline Hari & Konsentrasi (ppm) \\
\hline 1 & 5,388 \\
\hline 3 & 10,12 \\
\hline 7 & 16,76 \\
\hline 9 & 22,68 \\
\hline 11 & 26,05 \\
\hline 14 & 28,89 \\
\hline
\end{tabular}

Sebagai bahan perbandingan, digunakan reagen Griess yang biasanya digunakan pada penentuan nitrit dalam ikan bawal putih (Pampus argenteus). Larutan standar yang digunakan pada reagen Griess sama seperti larutan standar yang digunakan dalam reagen 3-amina-7-dimetilamina-2-metilfenazin hidroklorida. Hal ini dilakukan agar tidak 
terdapat perbedaan konsentrasi larutan standar yang digunakan pada kedua reagen. Nilai absorbansi larutan standar nitrit yang diperoleh menggunakan reagen Griess disajikan pada Tabel 3. Kurva kalibrasi absorbansi vs konsentrasi larutan standar disajikan pada Gambar 2. Pada penggunaan reagen Griess, persamaan garis absorbansi vs konsentrasi larutan standar natrium nitrit yang diperoleh adalah sebesar $y=0,00602 x$ dengan regresi sebesar 0,98974.

Tabel 5. Kadar Nitrit dalam Daging Ikan Bawal Putih (Pampus argenteus) dengan Variasi Waktu Penyimpanan Tanpa Melalui Proses Freeze Dry Menggunakan Reagen 3-amina-7-dimetilamina-2metilfenazin Hidroklorida

\begin{tabular}{|c|c|}
\hline Hari & Konsentrasi (ppm) \\
\hline 1 & 4,085 \\
\hline 3 & 7,697 \\
\hline 7 & 11,90 \\
\hline 9 & 15,75 \\
\hline 11 & 17,35 \\
\hline 14 & 18,53 \\
\hline
\end{tabular}

Dari grafik pada Gambar 2 terlihat bahwa tidak terdapat perbedaan yang signifikan antara kurva kalibrasi yang menggunakan reagen 3-amina-7-dimetilamina-2-metilfenazin hidroklorida dengan kurva kalibrasi yang menggunakan reagen Griess. Namun, lebih disarankan menggunakan reagen 3-amina-7dimetilamina-2-metilfenazin hiroklorida dalam penentuan nitrit karena pembentukan senyawa azo yang hanya membutuhkan waktu selama 3 menit. Sedangkan pembentukan senyawa azo pada reagen Griess membutuhkan waktu selama 30 menit di tempat gelap.

\subsection{Preparasi Sampel Ikan Bawal Putih (Pampus argenteus)}

Sampel yang berupa ikan bawal putih diperoleh dari hasil tangkapan nelayan di Muara Angke dan memiliki ukuran rata-rata panjang $21 \mathrm{~cm}$ dan lebar $15 \mathrm{~cm}$ serta berat sebesar 500g. Sampel yang dipilih merupakan ikan segar yang diperoleh dari tangkapan nelayan. Sampel kemudian dipotong dan diambil hanya bagian daging ikannya. Hal ini dikarenakan, biasanya bagian yang dikonsumsi oleh manusia hanya bagian daging ikannya saja.

Tabel 6. Kadar Nitrit dalam Daging Ikan Bawal Putih (Pampus argenteus) Menggunakan Reagen 3amina-7-dimetilamina-2-metilfenazin hidroklorida Melalui Proses Freeze Dry dan Tanpa Melalui Proses Freeze Dry

\begin{tabular}{|c|c|}
\hline Konsentrasi I (ppm) & $\begin{array}{c}\text { Konsentrasi II } \\
(\mathrm{ppm})\end{array}$ \\
\hline 5,388 & 4,085 \\
\hline 10,12 & 7,697 \\
\hline 16,76 & 11,90 \\
\hline 22,68 & 15,75 \\
\hline 26,05 & 17,35 \\
\hline 28,89 & 18,53 \\
\hline
\end{tabular}

Potongan daging ikan kemudian diblender untuk mendapatkan potongan daging kasar. Tahap selanjutnya ialah ikan difreeze-drykan menggunakan alat freeze-dryer. Tujuan tahap ini adalah untuk menghilangkan kandungan air yang terdapat dalam daging ikan, sehingga kandungan nitrit yang diukur berasal dari daging ikan saja. Namun, juga ingin diteliti kandungan nitrit dalam ikan basah sehingga terdapat sampel ikan yang tidak melalui tahap freeze drying. Keingintahuan ini berdasarkan pengolahan ikan oleh masyarakat yang biasanya digoreng hingga kering dan direbus. Pada ikan yang direbus terdapat kandungan air yang kemungkinan berpengaruh terhadap kadar nitrit di dalam ikan tersebut. Setelah itu, daging ikan digrinder hingga halus agar mudah diekstraksi. 
Tabel 7. Hasil Analisis Uji t Tidak Berpasangan Antara Konsentrasi Nitrit dalam Daging Ikan Bawal Putih (Pampus argenteus) Menggunakan Reagen 3Amina-7-Dimetilamina-2-Metilfenazin Hidroklorida Melalui Proses Freeze Dry dan Tanpa Proses Freeze Dry dengan Indeks Kepercayaan 95\%

\begin{tabular}{|c|c|c|c|c|}
\hline Proses & N & Rerata \pm s.b & $\begin{array}{c}\text { Perbedaan } \\
\text { Rerata }\end{array}$ & P \\
\cline { 1 - 2 } Freeze dry & 6 & $18,31 \pm 9,25$ & \multirow{2}{*}{5,76} & 0,176 \\
\cline { 1 - 3 } $\begin{array}{c}\text { Tanpa freeze } \\
\text { dry }\end{array}$ & 6 & $12,55 \pm 5,74$ & & \\
\hline
\end{tabular}

Daging ikan yang telah halus diambil sebanyak $0,5 \mathrm{~g}$ lalu diekstrak menggunakan natrium karbonat. Fungsi natrium karbonat adalah mengubah nitrit yang terkandung dalam daging ikan menjadi natrium nitrit. Selain itu, natrium karbonat dapat menghilangkan ion-ion pengganggu seperti $\mathrm{Ag}^{+}, \mathrm{Ca}^{2+}$ dan $\mathrm{Ba}^{2+}$ menjadi endapan karbonat.

Sampel ikan bawal putih (Pampus argenteus) segar disimpan dalam freezer lemari pendingin untuk memperlambat kebusukan. Sampel ikan didiamkan dengan waktu yang berbeda-beda yaitu 1 hari, 3 hari, 7 hari, 9 hari, 11 hari dan 14 hari. Hal tersebut dilakukan untuk melihat pengaruh waktu terhadap nitrit yang terkandung dalam ikan bawal putih (Pampus argenteus).

\subsection{Hasil Pengolahan Data}

\subsubsection{Penentuan Kadar Nitrit dalam Daging} Ikan Bawal Putih (Pampus argenteus) dengan Variasi Waktu Penyimpanan Melalui Proses Freeze Dry Menggunakan Reagen 3-amina-7dimetilamina-2-metilfenazin hidroklorida

Dari Tabel 4 terlihat bahwa semakin lama waktu pendiaman daging ikan bawal putih (Pampus argenteus) maka semakin besar kadar nitrit yang terkandung di dalamnya. Hal ini disebabkan terdapatnya bakteri Nitrosomonas yang dapat mengubah amonia menjadi nitrit. Bakteri Nitrosomonas bermetabolisme dengan baik pada temperatur
30-36ㄷ. Namun, bakteri Nitrosomonas tetap aktif pada suhu di bawah 6 으 bahkan pada suhu 0 으. Proses nitrifikasi yang dilakukan pada suhu yang lebih rendah dari suhu optimumnya akan menyebabkan laju pertumbuhan mikroba melambat dan berakibat pada peningkatan waktu retensinya. Pada kondisi tersebut proses nitrifikasi akan tetap berlangsung walaupun memerlukan waktu yang lebih lama. Semakin lama waktu pendiaman daging ikan bawal putih (Pampus argenteus) maka semakin banyak bakteri Nitrosomonas yang berkembang biak. Hal tersebut mengakibatkan semakin banyak proses nitrifikasi yang terjadi di dalam daging ikan bawal putih (Pampus argenteus) sehingga berdampak pada peningkatan kadar nitrit yang terkandung dalam daging ikan bawal putih (Pampus argenteus).

Kadar nitrit di air laut Muara Angke adalah sebesar $17,48 \times 10^{-3} \mathrm{ppm}$. Sedangkan kadar nitrit dalam daging ikan bawal putih (Pampus argenteus) pada hari pertama adalah sebesar 5,388ppm. Kadar nitrit pada ikan bawal putih (Pampus argenteus) yang jauh lebih tinggi dibandingkan kadar nitrit pada Muara Angke disebabkan oleh proses bioakumulasi dan biomagnifikasi.

Bioakumulasi adalah peningkatan konsentrasi zat kimia dalam tubuh mahluk hidup dalam waktu yang cukup lama, dibandingkan dengan konsentrasi zat kimia yang terdapat di alam. Bioakumulasi pada ikan bawal putih (Pampus argenteus) terjadi karena tingginya paparan nitrit dari air Muara Angke yang terus menerus dikonsumsi oleh ikan tersebut. Sedangkan biomagnifikasi adalah masuknya zat kimia dari lingkungan melalui rantai makanan yang mengakibatkan tingkat konsentrasi zat kimia dalam organisme sangat tinggi. Ikan bawal putih (Pampus argenteus) merupakan omnivora. Bioakumulasi yang terjadi pada fitoplankton maupun hewanhewan kecil di perairan Muara Angke 
mengakibatkan peningkatan kadar nitrit pada ikan bawal putih (Pampus argenteus).

Tabel 8. Kadar Nitrit dalam Daging Ikan Bawal Putih (Pampus argenteus) Melalui Proses Freeze Dry Menggunakan Reagen 3-amina-7-dimetilamina-2metilfenazin hidroklorida dan Reagen Griess

\begin{tabular}{|c|c|}
\hline Konsentrasi I (ppm) & Konsentrasi II (ppm) \\
\hline 5,388 & 5,150 \\
\hline 10,12 & 9,634 \\
\hline 16,76 & 15,78 \\
\hline 22,68 & 22,20 \\
\hline 26,05 & 25,42 \\
\hline 28,89 & 28,35 \\
\hline
\end{tabular}

Batas aman mengkonsumsi nitrit dalam satu hari adalah sebesar 0,07 $\mathrm{mg}$ nitrit per $\mathrm{kg}$ berat badan. Apabila berat manusia dewasa sebesar $60 \mathrm{~kg}$, maka kadar konsumsi nitrit yang diperbolehkan ialah 4,2mg. Sedangkan kadar nitrit dalam daging ikan bawal putih (Pampus argenteus) pada hari pertama adalah sebesar 5,388ppm. Maka, disarankan agar masyarakat tidak mendiamkan daging ikan bawal putih (Pampus argenteus) untuk dikonsumsi.

Berdasarkan uji statistik yang dilakukan, diperoleh nilai signifikansi 0,000 . Oleh karena nilai signifikansi kurang dari 0,05 , maka dapat diambil kesimpulan bahwa terdapat korelasi antara waktu pendiaman dengan dengan konsentrasi nitrit dalam daging ikan bawal putih (Pampus argenteus) adalah bermakna.

Nilai korelasi Pearson sebesar 0,991 menunjukkan korelasi positif dengan kekuatan korelasi yang sangat kuat. Korelasi positif bermakna semakin lama waktu pendiaman, maka semakin besar pula kadar nitrit dalam daging ikan bawal putih (Pampus argenteus).

\subsubsection{Penentuan Kadar Nitrit dalam Daging Ikan} Bawal Putih (Pampus argenteus) dengan Variasi Waktu Penyimpanan Tanpa Melalui Proses Freeze Dry Menggunakan
Reagen 3-amina-7-dimetilamina-2metilfenazin hidroklorida

Dari Tabel 5 terlihat bahwa semakin lama waktu pendiaman daging ikan bawal putih (Pampus argenteus) maka semakin besar kadar nitrit yang terkandung di dalamnya. Hal ini disebabkan terdapatnya bakteri Nitrosomonas yang dapat mengubah amonia menjadi nitrit. Bakteri Nitrosomonas bermetabolisme dengan baik pada temperatur 30-36ㄷ. Namun, bakteri Nitrosomonas tetap aktif pada suhu di bawah 6 으 bahkan pada suhu 0 으. Proses nitrifikasi yang dilakukan pada suhu yang lebih rendah dari suhu optimumnya akan menyebabkan laju pertumbuhan mikroba melambat dan berakibat pada peningkatan waktu retensinya.

Pada kondisi tersebut proses nitrifikasi akan tetap berlangsung walaupun memerlukan waktu yang lebih lama. Semakin lama waktu pendiaman daging ikan bawal putih (Pampus argenteus) maka semakin banyak bakteri Nitrosomonas yang berkembang biak.

Hal tersebut mengakibatkan semakin banyak proses nitrifikasi yang terjadi di dalam daging ikan bawal putih (Pampus argenteus) sehingga berdampak pada peningkatan kadar nitrit yang terkandung dalam daging ikan bawal putih (Pampus argenteus).

Kadar nitrit di air laut Muara Angke adalah sebesar $17,48 \times 10^{-3} \mathrm{ppm}$. Sedangkan kadar nitrit dalam daging ikan bawal putih (Pampus argenteus) pada hari pertama adalah sebesar 4,085ppm. Kadar nitrit pada ikan bawal putih (Pampus argenteus) yang jauh lebih tinggi dibandingkan kadar nitrit pada Muara Angke disebabkan oleh proses bioakumulasi dan biomagnifikasi. Bioakumulasi adalah peningkatan konsentrasi zat kimia dalam tubuh mahluk hidup dalam waktu yang cukup lama, dibandingkan dengan konsentrasi zat kimia yang terdapat di alam. Bioakumulasi pada ikan bawal putih (Pampus argenteus) terjadi karena tingginya paparan 
nitrit dari air Muara Angke yang terus menerus dikonsumsi oleh ikan tersebut. Sedangkan biomagnifikasi adalah masuknya zat kimia dari lingkungan melalui rantai makanan yang mengakibatkan tingkat konsentrasi zat kimia dalam organisme sangat tinggi. Ikan bawal putih (Pampus argenteus) merupakan omnivora. Bioakumulasi yang terjadi pada fitoplankton maupun hewan-hewan kecil di perairan Muara Angke mengakibatkan peningkatan kadar nitrit pada ikan bawal putih (Pampus argenteus).

Batas aman mengkonsumsi nitrit dalam satu hari adalah sebesar 0,07 mg nitrit per $\mathrm{kg}$ berat badan. Apabila berat manusia dewasa sebesar $60 \mathrm{~kg}$, maka kadar konsumsi nitrit yang diperbolehkan ialah 4,08mg. Sedangkan kadar nitrit dalam daging ikan bawal putih (Pampus argenteus) pada hari pertama adalah sebesar 4,085ppm. Maka, disarankan agar masyarakat tidak mendiamkan daging ikan bawal putih (Pampus argenteus) untuk dikonsumsi.

Berdasarkan uji statistik yang dilakukan, diperoleh nilai signifikansi 0,001. Oleh karena nilai signifikansi kurang dari 0,05 , maka dapat diambil kesimpulan bahwa terdapat korelasi antara waktu pendiaman dengan dengan konsentrasi nitrit dalam daging ikan bawal putih (Pampus argenteus) adalah bermakna. Nilai korelasi Pearson sebesar 0,981 menunjukkan korelasi positif dengan kekuatan korelasi yang sangat kuat. Korelasi positif bermakna semakin lama waktu pendiaman, maka semakin besar pula kadar nitrit dalam daging ikan bawal putih (Pampus argenteus).

\subsubsection{Perbandingan Kadar Nitrit dalam Daging} Ikan Bawal Putih (Pampus argenteus) Menggunakan Reagen 3-Amina-7Dimetilamina-2-Metilfenazin Hidroklorida Melalui Proses Freeze dry dan Tanpa Melalui Proses Freeze Dry

Konsentrasi I merupakan kadar nitrit dalam ikan bawal putih (Pampus argenteus) yang diperoleh melalui proses freeze dry sedangkan konsentrasi II merupakan kadar nitrit dalam ikan bawal putih (Pampus argenteus) yang diperoleh tanpa melalui proses freeze dry.

Dari Tabel 6 terlihat bahwa terdapat sedikit perbedaan antara kadar nitrit dalam daging ikan bawal putih (Pampus argenteus) yang diperoleh melalui proses freeze dry dengan kadar nitrit dalam daging ikan bawal putih (Pampus argenteus) yang diperoleh tanpa melalui proses freeze dry. Hal ini disebabkan kandungan air tidak mempengaruhi kandungan nitrit pada sampel sehingga kadar nitrit yang terukur baik yang melalui proses freeze dry maupun yang tanpa melalui proses freeze dry tersebut tidak jauh berbeda.

Tabel 9. Hasil Analisis Uji t Berpasangan Antara Konsentrasi Nitrit dalam Daging Ikan Bawal Putih (Pampus argenteus) Melalui Proses Freeze Dry Menggunakan Reagen 3-Amina-7-Dimetilamina-2Metilfenazin Hidroklorida dan Reagen Griess dengan Indeks Kepercayaan 95\%

\begin{tabular}{|c|c|c|c|c|}
\hline Konsentrasi & N & Rerata \pm s.b & $\begin{array}{c}\text { Perbedaan } \\
\text { Rerata } \pm \text { s.b }\end{array}$ & P \\
\hline $\begin{array}{c}\text { 3-amina-7- } \\
\text { dimetilamina-2- } \\
\text { metilfenazin } \\
\text { hidroklorida }\end{array}$ & 6 & $18,32 \pm 9,25$ & $0,56 \pm 0,24$ & 0,002 \\
\cline { 1 - 3 } Griess & 6 & $17,76 \pm 9,16$ & & \\
\hline
\end{tabular}

Berdasarkan uji statistik pada Tabel 7, diperoleh nilai signifikansi 0,176 . Oleh karena nilai signifikansi lebih dari 0,005, maka dapat diambil kesimpulan bahwa terdapat perbedaan konsentrasi nitrit dalam daging ikan bawal putih (Pampus argenteus) menggunakan reagen 3-amina-7dimetilamina-2-metilfenazin hidroklorida melalui proses freeze dry dan tanpa melalui proses freeze dry adalah tidak bermakna. Hal ini disebabkan proses freeze dry tidak mempengaruhi konsentrasi nitrit yang terkandung dalam daging ikan bawal putih (Pampus argenteus). Peningkatan konsentrasi nitrit bergantung pada lamanya waktu 
penyimpanan dimana pada saat tersebut terjadi proses nitrifikasi. Proses nitrifikasi

Tabel 10. Kadar Nitrit dalam Daging Ikan Bawal Putih (Pampus argenteus) Tanpa Melalui Proses Freeze Dry Menggunakan Reagen 3-amina-7dimetilamina-2-metilfenazin hidroklorida dan Reagen Griess

\begin{tabular}{|c|c|}
\hline Konsentrasi I (ppm) & Konsentrasi II (ppm) \\
\hline 4,085 & 3,987 \\
\hline 7,697 & 7,253 \\
\hline 11,90 & 11,46 \\
\hline 15,75 & 15,39 \\
\hline 17,35 & 16,89 \\
\hline 18,53 & 17,83 \\
\hline
\end{tabular}

merupakan proses perubahan amonia menjadi yang mengakibatkan konsentrasi nitrit dalam daging ikan bawal putih putih (Pampus argenteus) meningkat.

Sebagai bahan perbandingan, ditentukan kadar nitrit yang terkandung dalam ikan bawal putih (Pampus argenteus) menggunakan reagen Griess.

\subsubsection{Perbandingan Kadar Nitrit dalam Daging} Ikan Bawal Putih (Pampus argenteus) Melalui Proses Freeze Dry Menggunakan Reagen 3-Amina-7-Dimetilamina-2Metilfenazin Hidroklorida dan Reagen Griess

Berdasarkan Tabel 8, konsentrasi I merupakan kadar nitrit dalam ikan bawal putih (Pampus argenteus) yang diperoleh menggunakan reagen 3-amina-7dimetilamina-2-metilfenazin hidroklorida sedangkan konsentrasi II merupakan kadar nitrit dalam ikan bawal putih (Pampus argenteus) yang diperoleh menggunakan reagen Griess.

Dari Tabel 8 terlihat bahwa terdapat sedikit perbedaan antara kadar nitrit dalam daging ikan bawal putih (Pampus argenteus) yang diperoleh menggunakan reagen 3-amina- 7-dimetilamina-2-metilfenazin hidroklorida dengan kadar nitrit dalam daging ikan bawal putih (Pampus argenteus) yang diperoleh menggunakan reagen Griess. Hal ini disebabkan sampel yang digunakan pada kedua pengukuran merupakan sampel yang sama sehingga kadar nitrit yang terukur menggunakan kedua reagen tersebut tidak jauh berbeda.

Berdasarkan Tabel 9, diperoleh nilai signifikansi 0,002. Oleh karena nilai signifikansi kurang dari 0,005, maka dapat diambil kesimpulan bahwa terdapat perbedaan konsentrasi nitrit dalam daging ikan bawal putih (Pampus argenteus) melalui proses freeze dry menggunakan reagen 3-amina-7dimetilamina-2-metilfenazin hidroklorida dan reagen Griess adalah bermakna. Perbedaan rerata antara konsentrasi nitrit dalam daging ikan bawal (Pampus argenteus) melalui proses freeze dry menggunakan reagen 3-amina-7dimetilamina-2-metilfenazin hidroklorida dan reagen Griess adalah sebesar 0,56 0,24.

Tabel 11. Hasil Analisis Uji t Berpasangan Antara Konsentrasi Nitrit dalam Daging Ikan Bawal Putih (Pampus argenteus) Tanpa Melalui Proses Freeze Dry Menggunakan Reagen 3-Amina-7 Dimetilamina-2-Metilfenazin Hidroklorida dan Reagen Griess dengan Indeks Kepercayaan 95\%

\begin{tabular}{|c|c|c|c|c|}
\hline Konsentrasi & $\mathrm{N}$ & $\begin{array}{c}\text { Rerata } \pm s . \\
\text { b }\end{array}$ & $\begin{array}{l}\text { Perbedaan } \\
\text { Rerata } \pm \text { s.b }\end{array}$ & $\mathrm{P}$ \\
\hline $\begin{array}{c}\text { 3-amina-7- } \\
\text { dimetilamin } \\
\text { a-2- } \\
\text { metilfenazin } \\
\text { hidroklorida }\end{array}$ & 6 & $\begin{array}{c}12,55 \pm 5,7 \\
4\end{array}$ & \multirow[t]{2}{*}{$0,41 \pm 0,19$} & \multirow[t]{2}{*}{$\begin{array}{c}0,00 \\
3\end{array}$} \\
\hline Griess & 6 & $\begin{array}{c}12,14 \pm 5,6 \\
0\end{array}$ & & \\
\hline
\end{tabular}

3.4.5 Perbandingan Kadar Nitrit dalam Daging Ikan Bawal (Pampus argenteus) Tanpa Melalui Proses Freeze Dry Menggunakan Reagen 3-Amina-7-Dimetilamina-2Metilfenazin Hidroklorida dan Reagen Griess.

Berdasarkan Tabel 10, konsentrasi I merupakan kadar nitrit dalam ikan bawal putih (Pampus argenteus) yang diperoleh 
menggunakan reagen 3-amina-7-

dimetilamina-2-metilfenazin hidroklorida sedangkan konsentrasi II merupakan kadar nitrit dalam ikan bawal putih (Pampus argenteus) yang diperoleh menggunakan reagen Griess.

Dari Tabel 10 terlihat bahwa terdapat sedikit perbedaan antara kadar nitrit dalam daging ikan bawal putih (Pampus argenteus) yang diperoleh menggunakan reagen 3-amina7-dimetilamina-2-metilfenazin hidroklorida dengan kadar nitrit dalam daging ikan bawal putih (Pampus argenteus) yang diperoleh menggunakan reagen Griess. Hal ini karena sampel yang digunakan pada kedua pengukuran merupakan sampel yang sama, sehingga kadar nitrit yang terukur menggunakan kedua reagen tersebut tidak jauh berbeda.

Berdasarkan Tabel 11, diperoleh nilai signifikansi 0,003 . Oleh karena nilai signifikansi kurang dari 0,005, maka dapat diambil kesimpulan bahwa terdapat perbedaan konsentrasi nitrit dalam daging ikan bawal putih (Pampus argenteus) tanpa melalui proses freeze dry menggunakan reagen 3amina-7-dimetilamina-2-metilfenazin

hidroklorida dan reagen Griess adalah bermakna. Perbedaan rerata antara konsentrasi nitrit dalam daging ikan bawal (Pampus argenteus) tanpa melalui proses freeze dry menggunakan reagen 3-amina-7dimetilamina-2-metilfenazin hidroklorida dan

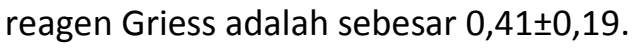

Dari data-data tersebut terlihat bahwa tidak terdapat perbedaan yang signifikan antara kadar nitrit pada ikan bawal putih (Pampus argenteus) yang diperoleh menggunakan reagen 3-amina-7dimetilamina-2-metilfenazin hidroklorida dengan kadar nitrit pada ikan bawal putih (Pampus argenteus) yang diperoleh menggunakan reagen Griess. Namun, lebih disarankan menggunakan reagen 3-amina-7dimetilamina-2-metilfenazin hiroklorida dalam penentuan nitrit karena pembentukan senyawa azo yang hanya membutuhkan waktu selama 3 menit. Sedangkan pembentukan senyawa azo pada reagen Griess membutuhkan waktu selama 30 menit di tempat gelap. Selain itu, reagen Griess biasa digunakan sebagai pewarna bakteri gram negatif. Kehadiran bakteri Nitrosomonas yang merupakan bakteri gram negatif dikhawatirkan dapat mengganggu pewarnaan yang dapat mempengaruhi nilai absorbansi sampel ikan bawal putih (Pampus argenteus).

\section{Kesimpulan}

Reagen 3-amina-7-dimetilamina-2metilfenazin hidroklorida dapat bertindak sebagai reagen pembentuk warna ketika direaksikan dengan nitrit, oleh karena itu reagen 3-amina-7-dimetilamina-2-metilfenazin hidroklorida dapat digunakan untuk menentukan kadari nitrit dalam ikan bawal putih (Pampus argenteus). Sampel ikan bawal putih (Pampus argenteus) diperoleh dari hasil tangkapan nelayan Muara Angke. Konsentrasi optimum reagen 3-amina-7-dimetilamina-2metilfenazin hidroklorida adalah 0,0021\% (b/v). Kadar nitrit dalam daging ikan bawal putih (Pampus argenteus) melalui proses freeze dry saat didiamkan selama satu hari adalah sebesar 5,388ppm, sedangkan tanpa melalui freeze dry adalah sebesar 4,085ppm. Kadar nitrit dalam daging ikan bawal putih (Pampus argenteus) melalui proses freeze dry saat didiamkan selama empat belas hari adalah sebesar 28,89ppm, sedangkan tanpa melalui freeze dry adalah sebesar 18,53ppm. Semakin lama ikan bawal putih (Pampus argenteus) didiamkan, maka konsentrasi nitrit yang terkandung semakin meningkat. Tidak terdapat perbedaan antara konsentrasi nitrit dalam daging ikan bawal (Pampus argenteus) yang mengalami proses freeze dry dan tidak mengalami proses freeze dry.

Untuk keperluan penelitian disarankan penentuan konsentrasi nitrit dalam hasil laut lain, yaitu kerang, udang, rumput laut yang berasal dari laut tercemar di Indonesia 


\section{Daftar Pustaka}

1. Argonne National Laboratory, EVS. 2005. Nitrate and Nitrite. Human Health Fact Sheet. http://www.epa.gov/OGWDW/dwh/c-ioc/nitrates.html, 21 September 2012. pk 20:49 WIB.

2. L'hirondel, J. 2002. Nitrate and Man:Toxic, Harmless or Beneficial. New York: CABI Publishing.

3. Ruse, M. 1999. Nitrates and Nitrites. http://www.inchem.org/nitrates\&nitrites.html., 23 Oktober 2012. pk 20:58 WIB.

4. Rogers, M., Vaughan, T., Davis, S. 1995. Consumption of Nitrate, Nitrite, and Nitrosodimethylamine and The Risk of Upper Aerodigestive Tract Cancer. Cancer Epidemiology, Biomarkers \& Prevention. 4: 29-36.

5. Prartono, T., Hasena, T. 2009. Kinetic Study of Phosphor and Nitrogen Compounds From Sedimentary Re-Suspension. Jurnal IImu dan Teknologi Kelautan Tropis. 1: 1-8.

6. Lewis, W., Morris, D. 1986. Toxicity of Nitrite to Fish: A Review. Transactions of the American Fisheries Society. 115: 183-195.

7. Direktorat Jenderal Perikanan Tangkap. 2007. Statistik Perikanan Tangkap di Laut Menurut Wilayah Pengelolaan Perikanan (WPP). 2002-2006. Jakarta: Departemen Kelautan dan Perikanan.

8. Michalsky, R., Kurzyca, I. 2006. Determination of Nitrogen Species (Nitrate, Nitrite and Ammonia lons) in Enviromental Samples. Polish Journal of Environmental Studies. 15: 5-18.

9. Gayathri, N., Balasubramanian, N. 1999. Spectrophotometric Determination of Nitrogen Dioxide, Nitrite and Nitrate with Neutral Red. Analysis, 27: 174-181. 